\title{
HUBUNGAN REWARD DAN PUNISHMENT DENGAN DISIPLIN KERJA PADA KARYAWAN RUMAH SAKIT GRANDMED LUBUK PAKAM KABUPATEN DELI SERDANG
}

\section{ARIF SUJATMIKOㄹ, RAHMAD GURUSINGA ${ }^{2}$, ISKANDAR MARKUS SEMBIRING ${ }^{3}$, NOVITA BR GINTING MUNTHE ${ }^{4}$, INDAH PRATIWI5}

$1,2,3,4,5$ INSTITUT KESEHATAN MEDISTRA LUBUK PAKAM

Jl. Sudirman No. 38 Lubuk Pakam Kab. Deli Serdang, Sumatera Utara

Email: arifsujatmiko@gmail.com

DOI : $10.35451 /$ jkf.v3i1.515

\begin{abstract}
Grandmed Lubuk Pakam Hospital applies reward and punishment in completing employee work discipline that must be in accordance with hospital regulations. Good rewards and punishments can motivate employees to improve work discipline and help employees achieve effective performance. This study aims to determine the Relationship of Reward and Punishment with Work Discipline in Employees of the Grandmed Lubuk Pakam Hospital in 2020. This type of quantitative research is analytic survey using cross sectional design. The sample in this study was taken by purposive sampling of 48 employees. Analysis using the Chi-Square test with a confidence level of $95 \%$, $a=0.05$. The results of the research between reward and work discipline show that there is a significant relationship between reward and work discipline in the employees of Grandmed Lubuk Pakam Hospital in 2020, $p$ value $(0.022)<a(0.05)$ is obtained. While the results of research between punishment with work discipline that shows there is a significant relationship between punishment with work discipline on employees of the Grandmed Lubuk Pakam Hospital in 2020. From the Chi Square test results obtained $p$ value (0.036) <a (0.05). It is expected that the hospital should pay more attention to the rewards and punishments for employees to further improve discipline, work motivation, work morale so that they can be maintained or further improved and it is advisable to pay more attention to work discipline to employees by giving reprimands or punishment to employees who work discipline is not good so the bias is even better.
\end{abstract}

Keywords: Reward, Punishment, and Work Discipline

\section{PENDAhULUAN}

Kedisiplinan pada dasarnya merupakan suatu hal yang harus dijalankan setiap organisasi, karena tanpa dukungan disiplin kerja karyawan yang baik, sulit bagi perusahaan untuk mewujudkan tujuannya. Kedisiplinan sangat berguna untuk meningkatkan keterampilan dan kemampuan para karyawan guna menunjang perubahan sikap para karyawan yang berdasarkan motivasi untuk berprestasi di dalam suatu organisasi. Jadi kedisiplinan adalah kunci keberhasilan suatu perusahaan dalam mencapai tujuannya (Hasibuan, 2014 dan Saputra, 2017).

Untuk membantu karyawan mencapai kinerja yang efektif, organisasi dapat memperhatikan beberapa hal lain selain disiplin kerja, yaitu reward dan punishment. Reward atau penghargaan merupakan segala 
sesuatu yang diterima para karyawan atau pegawai dari organisasi kerjanya, sebagai penghargaan dan balas jasa untuk kerja mereka (Handoko, 2011). Punishment atau sanksi dan hukuman dalam suatu organisasi kerja merupakan ancaman yang bertujuan untuk memperbaiki pelanggaran, memelihara peraturan yang berlaku dan memberikan pelajaran bagi pelanggaran (Mangkunegara, 2015).

Setiap karyawan memiliki tujuan yang berbeda-beda dalam bekerja, sebagian karyawan bekerja hanya untuk mendapatkan uang, ada yang bekerja karena alasan gengsi dan ada juga yang bekerja karena suka dengan pekerjaan tertentu, bahkan ada juga karyawan yang tidak tau apa yang menjadi motif mereka dalam bekerja. Oleh karena itu ada teknik dan strategi yang menjamin bahwa setiap karyawan akan memiliki moral dan disiplin kerja tinggi (Siahaan, 2013 dan Arum, 2016).

Dari hasil survei awal yang dilakukan peneliti pada Rumah Sakit Grandmed yang berada di Kecamatan Lubuk Pakam Kabupaten Deli Serdang. Berdasarkan hasil pengamatan dan wawancara yang peneliti lakukan di Rumah Sakit Grandmed Lubuk Pakam, bentuk reward yang diberikan kepada karyawan terbaik diperoleh dari kuesioner yang dibagikan dan diisi oleh karyawan, dari kuesioner yang diisi oleh karyawan didapatkan nama-nama kandidat calon karyawan terbaik dan kemudian dirapatkan oleh manajemen untuk mendapatkan tiga orang karyawan terbaik dalam setiap bulannya. Karyawan terbaik akan mendapatkan sertifikat penghargaan dan uang nominal sebagai bentuk prestasi menjadi karyawan terbaik di bulan itu. Untuk punishment yang diterapkan di Rumah Sakit Grandmed Lubuk Pakam, pihak manajemen memberikan sanksi kepada karyawan yang tidak finger atau terlambat datang saat bekerja. Sanksi di awal yang diberikan kepada karyawan berupa teguran dan apabila dilakukan secara berturut-turut maka manajemen memberikan Surat Peringatan (SP) 1 , dan jika melakukan kesalahan yang sama maka akan diberikan SP 2 dan 3. Jika karyawan telah mendapatkan SP 3 maka pihak manajemen mengeluarkan surat pengunduran diri kepada karyawan tersebut. Jika karyawan tidak hadir dalam waktu 5 hari secara berturut-turut maka pihak manajemen menganggap karyawan tersebut telah resign atau mengundurkan diri.

Maka dilakukan penelitian Hubungan Reward dan Punishment dengan Disiplin Kerja Pada Karyawan Rumah Sakit Grandmed Lubuk Pakam.

\section{METODE PENELITIAN}

Jenis penelitian ini adalah penelitian kuantitatif yang bersifat survey analitik, menggunakan desain cross sectional yang bertujuan untuk mengetahui Hubungan Reward dan Punishment dengan Disiplin Kerja Pada Karyawan Rumah Sakit Grandmed Lubuk Pakam. Sampel dalam penelitian ini diambil dengan Purposive Sampling sebanyak 48 karyawan bagian kantor Rumah Sakit Grandmed Lubuk Pakam. Pengumpulan data dengan menggunakan data primer dan data sekunder. Wawancara kepada responden dengan berpedoman pada kuesioner yang telah dipersiapkan merupakan teknik yang digunakan dalam mengumpulkan data primer. Sedangkan data sekunder diperoleh dari bagian administrasi data di Rumah Sakit Grandmed Lubuk Pakam. Setelah data terkumpul, Kemudian diolah dengan menggunakan menggunakan uji Chi-Square dengan tingkat kepercayaan 95\%, $a=0,05$, berarti hipotesis alternatif $(\mathrm{Ha})$ pada penelitian diterima yaitu Ada Hubungan 
Reward dan Punishment dengan Disiplin Kerja Pada Karyawan Rumah Sakit Grandmed Lubuk Pakam.

\section{HASIL PENELITIAN}

Tabel 1. Distribusi Responden Berdasarkan Reward selama bekerja pada Karyawan Bagian Kantor Rumah

Sakit Grandmed Lubuk Pakam

\begin{tabular}{lcc}
\hline \multicolumn{1}{c}{ Reward } & $\mathrm{f}$ & $\%$ \\
\hline Tidak Pernah & 7 & 14,6 \\
Pernah & 41 & 85,4 \\
\hline Total & 48 & 100,0 \\
\hline
\end{tabular}

Berdasarkan Tabel 1 menunjukkan dari 48 orang responden pada karyawan bagian kantor di Rumah Sakit Grandmed Lubuk Pakam yang tidak pernah mendapatkan reward selama bekerja sebanyak 7 orang $(14,6 \%)$, dan karyawan yang pernah mendapatkan reward selama bekerja sebanyak 41 orang $(85,4 \%)$.

Tabel 2. Distribusi Responden

Berdasarkan Punishment selama bekerja pada Karyawan Bagian Kantor Rumah Sakit Grandmed Lubuk Pakam

\begin{tabular}{lcc}
\hline \multicolumn{1}{c}{ Punishment } & $\mathrm{f}$ & $\%$ \\
\hline Tidak Pernah & 44 & 91,7 \\
Pernah & 4 & 8,3 \\
\hline Total & 48 & 100,0 \\
\hline
\end{tabular}

Berdasarkan Tabel 2 menunjukkan dari 48 orang responden pada karyawan bagian kantor di Rumah Sakit Grandmed Lubuk Pakam yang tidak pernah mendapatkan punishment selama bekerja sebanyak 44 orang $(91,7 \%)$, dan karyawan yang pernah mendapatkan punishment selama bekerja sebanyak 4 orang $(8,3 \%)$.

Tabel 3. Distribusi Responden

Berdasarkan Disiplin Kerja pada Karyawan Bagian Kantor Rumah Sakit Grandmed Lubuk Pakam

\begin{tabular}{lcc}
\hline \multicolumn{1}{c}{ Disiplin Kerja } & $\mathrm{f}$ & $\%$ \\
\hline Tidak Disiplin & 7 & 14,6 \\
Disiplin & 41 & 85,4 \\
\hline \multicolumn{1}{c}{ Total } & 48 & 100,0 \\
\hline
\end{tabular}

Berdasarkan Tabel 3 menunjukkan bahwa dari 48 orang responden pada karyawan bagian kantor di Rumah Sakit Grandmed Lubuk Pakam, karyawan yang tidak disiplin sebanyak 7 orang $(14,6 \%)$, dan karyawan yang disiplin sebanyak 41 orang $(85,4 \%)$.

Tabel 4. Hubungan Reward dan Punishment dengan Disiplin Kerja Pada Karyawan Bagian Kantor Rumah Sakit Grandmed Lubuk Pakam

\begin{tabular}{|c|c|c|c|c|c|c|c|}
\hline \multicolumn{8}{|c|}{ Disiplin Kerja } \\
\hline \multicolumn{3}{|c|}{$\begin{array}{c}\text { Tidak } \\
\text { Disipli } \\
n\end{array}$} & \multicolumn{2}{|c|}{ Disiplin } & \multicolumn{2}{|c|}{ Total } & $\begin{array}{c}p \\
\text { value }\end{array}$ \\
\hline Reward & $\mathrm{N}$ & $\%$ & $n$ & $\%$ & $\mathrm{n}$ & $\%$ & \\
\hline $\begin{array}{l}\text { Tidak } \\
\text { Pernah }\end{array}$ & 3 & 6,3 & 4 & 8,3 & 7 & $\begin{array}{c}14 \\
6\end{array}$ & 0,022 \\
\hline Pernah & 4 & 8,3 & $\begin{array}{l}3 \\
7\end{array}$ & 77,1 & $\begin{array}{l}4 \\
1\end{array}$ & $\begin{array}{c}85 \\
4\end{array}$ & \\
\hline Total & 7 & $\begin{array}{c}14 \\
6\end{array}$ & $\begin{array}{l}4 \\
1 \\
\end{array}$ & 85,4 & $\begin{array}{l}4 \\
8\end{array}$ & $\begin{array}{l}10 \\
0,0\end{array}$ & \\
\hline $\begin{array}{l}\text { Punish } \\
\text { ment }\end{array}$ & $\mathrm{N}$ & $\%$ & $\mathrm{~N}$ & $\%$ & $\mathrm{~N}$ & $\%$ & \\
\hline $\begin{array}{l}\text { Tidak } \\
\text { Pernah }\end{array}$ & 5 & $\begin{array}{c}10 \\
4\end{array}$ & $\begin{array}{l}3 \\
9\end{array}$ & 81,3 & $\begin{array}{l}4 \\
4\end{array}$ & $\begin{array}{l}91, \\
7 \%\end{array}$ & 0,036 \\
\hline Pernah & 2 & 4,2 & 2 & 4,2 & 4 & $\begin{array}{c}8,3 \\
\%\end{array}$ & \\
\hline Total & 7 & $\begin{array}{c}14 \\
6\end{array}$ & $\begin{array}{l}4 \\
1 \\
\end{array}$ & 85,4 & $\begin{array}{l}4 \\
8\end{array}$ & $\begin{array}{l}10 \\
0,0 \\
\end{array}$ & \\
\hline
\end{tabular}

Berdasarkan tabel 4, maka dapat diketahui bahwa dari 7 karyawan $(14,6 \%)$ yang tidak pernah mendapatkan reward terdapat 4 karyawan $(8,3 \%)$ memiliki disiplin kerja yang baik, sedangkan 3 karyawan $(6,3 \%)$ memiliki disiplin kerja yang tidak baik. Dari 41 karyawan $(85,4 \%)$ yang pernah mendapatkan reward terdapat 37 karyawan $(77,1 \%)$ memiliki disiplin kerja yang baik, dan sebanyak 4 karyawan (8,3\%) memiliki disiplin kerja yang tidak baik. Hasil uji Chi Square diperoleh nilai $p(0,022)<$ a $(0,05)$, hal ini berarti ada hubungan yang signifikan antara reward dengan disiplin kerja pada karyawan Rumah 
Sakit Grandmed Lubuk Pakam Tahun 2020.

Dari 44 karyawan $(91,7 \%)$ yang tidak pernah mendapatkan punishment terdapat 39 karyawan (81,3\%) memimiliki disiplin kerja yang baik, sedangkan 5 karyawan (10,4\%) memiliki disiplin kerja yang tidak baik. Dari 4 karyawan $(8,3 \%)$ yang pernah mendapatkan punishment terdapat 2 karyawan $(4,2 \%)$ memiliki disiplin kerja yang baik, dan sebanyak 2 karyawan $(4,2 \%)$ memiliki disiplin kerja yang tidak baik. Hasil uji Chi Square diperoleh nilai $p(0,036)<a(0,05)$, hal ini berarti ada hubungan yang signifikan antara punishment dengan disiplin kerja pada karyawan Rumah Sakit Grandmed Lubuk Pakam Tahun 2020

\section{PEMBAHASAN}

\section{a. Reward}

Berdasarkan hasil dari tabel 1 menunjukkan bahwa di Rumah Sakit Grandmed, reward yang sudah diterapkan untuk karyawan adalah berupa pemberian sertifikat dan uang nominal kepada 3 orang karyawan terbaik dalam setiap bulannya. Reward tersebut sudah berjalan dengan baik dan diharapkan dengan pemberian penghargaan yang ikut mempengaruhi kedisiplinan karyawan di Rumah Sakit Grandmed Lubuk Pakam.

Menurut Handoko (2017), reward sebagai bentuk apresiasi usaha untuk mendapatkan tenaga kerja yang professional sesuai dengan tuntutan jabatan diperlakukan suatu pembinaan yang berkesinambungan, yaitu suatu usaha kegiatan perencanaan, pengorganisasian, penggunaan dan pemeliharaan tenaga kerja agar mampu melaksanakan tugas dengan efektif dan efisien. Dalam meningkatkan disiplin kerja dalam sebuah organisasi reward berperan penting. Dengan adanya reward akan berfungsi sebagai pemotivasi yang dapat meningkatkan disiplin kerja karyawan secara positif karena dengan adanya system reward maka kinerja dan ketaatan pada perusahaan akan meningkat, sehingga mereka akan berusaha bekerja lebih baik guna mendapatkan reward yang dijanjikan oleh rumah sakit.

Reward berpengaruh positif terhadap kepuasan karyawan, sehingga dapat menyebabkan para karyawan bekerja lebih giat dan dengan sendirinya akan berpengaruh pada tujuan yang akan dicapai oleh perusahaan yang bersangkutan. Metode ini bisa mengasosiasikan perbuatan dan kelakuan seseorang dengan perasaan bahagia dan biasanya akan membuat mereka melakukan suatu perbuatan yang baik secara berulang-ulang. Selain itu motivasi penghargaan juga bertujuan agar seseorang menjadi giat lagi usahanya untuk memperbaiki atau meningkatkan prestasi yang telah dicapai. Jadi dapat disimpulkan penghargaan dapat memberikan kepuasan dan kecintaan karyawan terhadap organisasi atau pekerjaanya. Jika kecintaan karyawan semakin baik terhadap pekerjaan, maka kedisiplinan mereka akan baik pula.

\section{b. Punishment}

Berdasarkan hasil dari tabel 2 dapat diketahui bahwa teguran atau peringatan karyawan di Rumah Sakit Grandmed Lubuk Pakam sudah baik, akan tetapi masih perlu terus untuk ditingkatkan kembali agar para karyawan lebih berdisiplin dan lebih memperhatikan peraturan yang ada di Rumah Sakit Grandmed Lubuk Pakam.

Menurut Hasibuan (2014), salah satu peran penting dari punishment adalah untuk memelihara kedisiplinan karyawan. Punishment diperlukan dalam meningkatkan kedisiplinan dan 
mendidik karyawan supaya menaati semua peraturan perusahaan. Dengan keadilan dan ketegasan, sasaran pemberian punishment akan tercapai. Peraturan tanpa dibarengi pemberian punishment yang tegas bagi pelanggarnya bukan menjadi alat pendidik bagi karyawan. Pada beberapa, kondisi tertentu, penggunaan punishment dapat lebih efektif untuk merubah perilaku karyawan atau pegawai, yaitu dengan mempertimbangkan: waktu, intensitas, jadwal, klarifikasi, dan impersonalitas (tidak bersifat pribadi). Punishment yang diterapkan di Rumah Sakit Grandmed Lubuk Pakam yaitu, pihak manajemen memberikan sanksi kepada karyawan yang tidak finger atau terlambat datang saat bekerja. Sanksi di awal yang diberikan kepada karyawan berupa teguran dan apabila dilakukan secara berturut-turut maka manajemen memberikan Surat Peringatan (SP) 1, 2, dan 3. Jika karyawan telah mendapatkan SP 3 maka pihak manajemen mengeluarkan surat pengunduran diri kepada karyawan tersebut. Jika karyawan tidak hadir dalam waktu 5 hari secara berturut-turut maka pihak manajemen menganggap karyawan tersebut telah resign.

Menurut Hidayat (2018), teguran merupakan pemberiatahuan kepada seseorang tentang kesalahan yang telah dilakukan dan dia telah mengetahui aturan yang seharusnya untuk dipatuhi. Sedangkan, peringatan merupadan pemberitahuan atas kesalahan kepada seseorang yang telah berulang kali melakukan kesalahan dan telah ditegur berulang kali. Menurut pendapat peneliti, teguran atau peringatan karyawan di Rumah Sakit Grandmed Lubuk Pakam sudah baik, akan tetapi masih perlu terus untuk ditingkatkan kembali agar para karyawan lebih berdisiplin dan lebih memperhatikan peraturan yang ada di Rumah Sakit Grandmed Lubuk Pakam. Menurut pendapat peneliti, Rumah Sakit Grandmed Lubuk Pakam harus mempertahankan hukuman atas kesalahan agar dapat memberikan pembinaan kepada karyawan yang tidak berdisiplin atau kurang disiplin agar menjadi lebih baik lagi kedepannya dan lebih bertanggung jawab atas peraturan yang sudah ada.

\section{c. Disiplin Kerja}

Dari tabel 3 menunjukkan bahwa disiplin yang telah ditegakkan $\mathrm{Di}$ Rumah Sakit Grandmed Lubuk Pakam sudah baik karena lebih dari $50 \%$ responden memiliki disiplin yang tinggi. Berarti sebagian besar karyawan Rumah Sakit Grandmed Lubuk Pakam sebagian sudah mentaati peraturan yang ditetapkan oleh pimpinan.

Dalam membentuk disiplin kerja terdapat 8 faktor yang berpengaruh yaitu pertama tujuan dan kemampuan, pekerjaan yang diberikan kepada karyawan Rumah Sakit Grandmed Lubuk Pakam ternyata sesuai dengan kemampuan mereka masing-masing sehingga karyawan bekerja dengan sungguh-sungguh dan disiplin. Kedua teladan pimpinan, pimpinan Rumah Sakit Grandmed Lubuk Pakam menjadi pantauan bagi karyawannya sehingga pimpinan harus bersikap baik, disiplin, jujur, adil serta sesuai antara perkataan dan perbuatannya. Ketiga balas jasa (gaji dan kesejahteraan), karyawan Rumah Sakit Grandmed Lubuk Pakam mendapatkan gaji yang sesuai dengan jabatan masing-masing seacra adil dan mendapatkan asuransi tenaga kerja seperti BPJS Ketenagakerjaan sebagai kesejahteraan yang mereka terima. Keempat adalah keadilan, perlakuan pimpinan di Rumah Sakit Grandmed Lubuk Pakam terhadap karyawannya disamaratakan tanpa ada pengecualian 
sehingga karyawan akan merasa dirinya dianggap penting dan akan bekerja dengan sungguh-sungguh. Kelima pengawan, pimpinan Rumah Sakit Grandmed Lubuk Pakam mengawasi karyawannya secara langsung sehingga merasa diperhatikan dan mendapatkan arahan dari atasannya. Keenam hukuman, di Rumah Sakit Grandmed Lubuk Pakam menerapkan hukuman untuk para karyawan yang melanggar peraturan agar karyawan mematuhi peraturan yang telah ditetapkan oleh pimpinan rumah sakit. Ketujuh adalah ketegasan, atasan Rumah Sakit Grandmed Lubuk Pakam dalam memberikan hukuman kepada bawahannya yang terbukti melanggar peraturan. Yang terakhir adalah hubungan kemanusiaan, hubungan antar karyawan, antar atasan dengan bawahannya dan antara sesame karyawan di Rumah Sakit Grandmed Lubuk Pakam sangat baik sehingga kekeluargaan dalam wilayah kerja lebih terasa.

\section{d. Hubungan Reward dengan Disiplin Kerja pada Karyawan bagian Kantor Rumah Sakit Grandmed Lubuk Pakam Tahun 2020}

Hasil analisa data secara statistik dengan menggunaka uji Chi-Square menunjukkan bahwa ada hubungan yang signifikan antara reward dengan disiplin kerja pada karyawan Rumah Sakit Grandmed Lubuk Pakam tahun 2020, dimana $p$ value $(0,022)<a$ $(0,05)$.

Berdasarkan hasil yang didapat peneliti mengenai reward dengan disiplin kerja dari 7 karyawan (14,6\%) yang tidak pernah mendapatkan reward terdapat 4 karyawan (8,3\%) memiliki disiplin kerja yang baik, sedangkan 3 karyawan (6,3\%) memiliki disiplin kerja yang tidak baik. Dari 41 karyawan $(85,4 \%)$ yang pernah mendapatkan reward terdapat 37 karyawan $(77,1 \%)$ memiliki disiplin kerja yang baik, dan sebanyak 4 karyawan $(8,3 \%)$ memiliki disiplin kerja yang tidak baik.

Sama halnya dengan penelitian yang dilakukan Rumiris (2016) bahwa terdapat pengaruh antara reward terhadap disiplin karyawan pada PT. Perkebunan Nusantara III Rambutan dengan nilai $p$ value $0,000<0,05$ (Rumiris, 2016). Tetapi berdasarkan penelitian yang dilakukan oleh Anwar (2016) bahwa tidak ada pengaruh reward terhadap peningkatan disiplin kerja karyawan PT. Tunggal Perkasa Plantation-3 Kecamatan Sampoiniet Kabupaten Aceh Jaya tahun 2016 dengan nilai $p$ value $=0,541$ (Anwar, 2016).

Menurut peneliti mengapa reward dapat berhubungan dengan disiplin kerja di karenakan reward menjadi salah satu alat yang dapat mengasosiakan perbuatan dan perlakuan karyawan dengan perasaan bahagia, senang dan biasanya dapat membuat mereka melakukan sesuatu yang baik secara berulang-ulang. Selain motivasi, reward juga bertujuan agar karyawan menjadi lebih giat lagi dalam memperbaiki atau meningkatkan prestasi yang telah dicapainya.

Penerapan reward memberikan dampak karyawan untuk lebih bersemangat dalam menjalankan tugas-tugasnya di rumah sakit. Reward merupakan bentuk pemberian balas jasa yang diberikan kepada seorang karyawan atas prestasi pekerjaan yang dilakukan. Selain reward yang diberikan rumah sakit sudah baik, faktor lain yang dapat menentukan kelangsungan hidup suatu rumah sakit adalah karyawan yang mampu menerapkan kedisiplinan dengan baik. Dengan karyawan mematuhi peraturan yang telah ditetapkan oleh rumah sakit 
dan mempunyai disiplin kerja yang tinggi maka akan menciptakan suasana rumah sakit lebih kondusif sehingga akan berdampak positif pada aktivitas rumah sakit. Karena pada dasarnya setiap rumah sakit mempunyai harapan agar karyawan rumah sakit dapat mematuhi peraturan yang telah ditetapkan.

\section{e. Hubungan Punishment dengan Disiplin Kerja pada Karyawan bagian Kantor Rumah Sakit Grandmed Lubuk Pakam Tahun 2020}

Hasil analisa data secara statistik dengan menggunaka uji Chi-Square menunjukkan bahwa ada hubungan yang signifikan antara punishment dengan disiplin kerja pada karyawan Rumah Sakit Grandmed Lubuk Pakam tahun 2020, dimana $p$ value $(0,036)$ $<$ a $(0,05)$.

Berdasarkan hasil yang didapat peneliti mengenai punishment dengan disiplin kerja dari 44 karyawan $(91,7 \%)$ yang tidak pernah mendapatkan punishment terdapat 39 karyawan $(81,3 \%)$ memimiliki disiplin kerja yang baik, sedangkan 5 karyawan (10,4\%) memiliki disiplin kerja yang tidak baik. Dari 4 karyawan $(8,3 \%)$ yang pernah mendapatkan punishment terdapat 2 karyawan $(4,2 \%)$ memiliki disiplin kerja yang baik, dan sebanyak 2 karyawan $(4,2 \%)$ memiliki disiplin kerja yang tidak baik.

Hasil penelitian ini sejalan dengan penelitian Puteri (2018) bahwa terdapat pengaruh yang signifikan antara punishment dengan disiplin kerja pada pegawai PT. Taspen (Persero) Kantor Cabang Utama Bandung di lihat dari nilai signifikan $0,000<0,05$ dan thitung sebesar 4,546 lebih besar dari ttabel yaitu 1,673.

Hasil penelitian ini sejalan dengan penelitian Faizal (2018) bahwa terdapat hubungan punishment dengan disiplin kerja pada karyawan Waroeng Spesial Sambal Yogyakarta dengan nilai $p$ value $=0,000$. Tetapi berdasarkan penelitian yang dilakukan oleh Anwar (2016) bahwa tidak ada pengaruh Punishment terhadap peningkatan disiplin kerja karyawan PT. Tunggal Perkasa Plantation-3 Kecamatan Sampoiniet Kabupaten Aceh Jaya tahun 2016 dengan nilai $p$ value $=0,076$ (Anwar, 2016).

Menurut peneliti mengapa punishment dapat berhubungan dengan disiplin kerja di karenakan punishment memiliki peran penting untuk meningkatkan kedisiplinan karyawan supaya mentaati semua peraturan. Punishment dapat menjadi ancaman hukuman bagi karyawan yang bertujuan untuk memperbaiki karyawan pelanggar aturan dan memberikan pelajaran pada pelanggar. Dengan adanya punishment dapat menjadi salah satu cara untuk mengurangi perilaku yang tidak dikehendaki dengan cara memberikan konsekuensi yang tidak menyenangkan terhadap perilaku itu.

Punishment diterapkan dengan tujuan memelihara peraturan yang berlaku agar segala tugas dan tanggung jawab dapat terlaksanakan dengan baik. Jadi, punishment merupakan bentuk reaksi dari pemimpin untuk menjaga dan meningkatkan disiplin karaywan, serta mendorong karyawan agar menjadi lebih baik, lebih berkualitas, dan bertanggung jawab dengan tugas yang dibebankan.

\section{KESIMPULAN}

Kesimpulan yang dapat ditarik pada penelitian ini bahwa dari 48 orang responden pada karyawan bagian kantor di Rumah Sakit Grandmed Lubuk Pakam yang tidak pernah mendapatkan reward selama bekerja sebanyak 7 orang $(14,6 \%)$, dan 
karyawan yang pernah mendapatkan reward selama bekerja sebanyak 41 orang $(85,4 \%)$; Yang tidak pernah mendapatkan punishment selama bekerja sebanyak 44 orang $(91,7 \%)$, dan karyawan yang pernah mendapatkan punishment selama bekerja sebanyak 4 orang (8,3\%). Dan ada hubungan yang signifikan antara reward (nilai $p=0,022$ ) dan punishment (nilai $p=0,036$ ) dengan disiplin kerja pada karyawan bagian kantor Rumah Sakit Grandmed Lubuk Pakam Tahun 2020.

Untuk membantu para karyawan dalam mencapai kinerja yang efektif, manajemen rumah sakit wajib selalu memperhatikan disiplin kerja, reward dan punishment. Sehingga motivasi kerja dan semangat kerja para karyawan tetap terjaga dengan baik guna memajukan rumah sakit.

\section{DAFTAR PUSTAKA}

Anwar, dan Dunuja, T. (2016). Pengaruh Sistem Reward Dan Punishment Terhadap Peningkatan Disiplin Kerja Karyawan Pt. Tunggal Perkasa Plantation-3 Kecamatan Sampoiniet Kabupaten Aceh Jaya. Jurnal Serambi Akademica, Vol. IV, No. 1. Universitas Serambi Mekkah.

Arum. (2016). Analisis Pengaruh Struktur Kepemilikan Terhadap Kinerja Perusahaan, Jurnal Pena, Vol. 19, No. 2.

Budiarti, K.A. (2019). Pengaruh Reward dan Punishment Terhadap Disiplin Kerja Pegawai BLUD Non PNS Rumah Sakit Paru Dungus Madiun.Stikes Bhskti Husada Mulia Madiun.

Handoko. T. Hani. (2011). Manajemen Sumber Daya Manusia. Yogyakarta : Edisi 2. BPPEYogjakarta.
Hasibuan, Melayu. (2016). Manajemen Sumber Daya Manusia. Jakarta : Bumi Aksara.

Hasibuan, S.P Melayu. (2014). Manajemen Sumber Daya Manusia. Bumi Aksara, Jakarta.

Hidayat, Faizal. (2018). Pengaruh Reward dan Punishment Terhadap Kinerja Karyawan Dengan Disiplin Kerja Sebagai Variabel Intervening di Waroeng Spesial Sambal Yogyakarta. Jurnal.

http://dspace.uii.ac.id/bitstream /handle/123456789/7340

Mangkunegara, Anwar Prabu. (2015). Manajemen Sumber Daya Manusia Perusahaan. Bandung : PT. Remaja Rosdakarya.

Puteri, Egga Novrizalia. (2018). Pengaruh Reward dan Punishment Terhadap Disiplin Kerja Pegawai. http://www.digilib.unsgd.ac.id/1 $\underline{6508 / \text { \&ved }=2 \text { ahUkEwieiYD33dD }}$ $\underline{\text { hAH.pdf }}$

Saputra, Dicky., dkk. (2017). Pengaruh Reward dan Punishment Terhadap Produktivitas Kerja Karyawan. http://ojs.unitaspdg.ac.id/index.php/manajemen /article/view/87.pdf

Siahaan, Rumiris. (2016). Pengaruh Reward Dan Punishment Terhadap Disiplin Kerja Karyawan Pada PT. Perkebunan Nusantara III Rambutan. Jurnal Ilmiah Bussiness Program, Vol. 1, No, 01, 17-26. https://ejournal.unsrat.ac.id/ind ex.php/emba/article/download/2 $\underline{5252 / 24948}$ 